\title{
Trude Nilsen
}

Department of Teacher Education and School Research, University of Oslo Carl Angell

Department of Physics, University of Oslo

Liv Sissel Grønmo

Department of Teacher Education and School Research, University of Oslo

\section{Mathematical competencies and the role of mathematics in physics education: A trend analysis of TIMSS Advanced 1995 and 2008}

"The book of nature is written in the language of mathematics." Galileo Galilei (1623), The Assayer

\section{Introduction and aims}

Society today is ever more dependent upon technological competence for the sustainable development of health, industry and environment; consequently society needs technologically competent citizens (Osborne \& Dillon, 2008). At the heart of such technological competence is physics, and physics necessitates mathematical competence (Redish, 2006). Physics and mathematics are strongly interrelated, and this relationship becomes more apparent as students advance in school. Mathematics is more than just a tool for working with physics problems; the discourse of physics is mathematical in nature (Uhden, Karam, Pietrocola, \& Pospiech, 2011).

It is hence a great concern that both mathematics and physics achievements in upper secondary school are in decline in a number of countries, including Sweden and Norway (Mullis, 2009), especially because previous research indicate that mathematical skills influence physics achievements (e.g. Lawrenz, Wood, Kirchhoff, Kim, \& Eisenkraft, 2009). However, the study of mathematics in physics is a relatively small field within physics education compared to, for instance, the field of conceptual change (Duit \& Treagust, 2012). Conceptual understanding deserves a great deal of attention in physics education; physics is often regarded as a particularly difficult school subject (see e.g., Angell, Guttersrud, Henriksen, \& Isnes, 2004; Carlone, 2003; Duit, Niedderer, \& Schecker, 2007; Osborne, 2001). However, the nature of the students' difficulties also involves the use of mathematics (Meltzer, 2002; Redish, 2006; Uhden et al., 2011).

Researchers have investigated the challenges that students experience with mathematics in physics (e.g. Buick, 2007; Hudson \& Liberman, 1982; Meltzer, 
2002; Redish, 2006; Tuminaro \& Redish, 2007), but this body of research on mathematics in physics education does not explore which particular mathematical competencies are pertinent to performance in physics tasks and assessment items. Duit (2007) concluded his review of physics education by stating that more research is needed "To design models of students' competency structures, drawing on data from achievement tests, favorably in a longitudinal perspective” (p. 623). Moreover, the increasing emphasis on competence-based curricula in educational initiatives around the world (De Jong, 2004; Mulder, Gulikers, Biemans, \& Wesselink, 2009; Westera, 2001) necessitates a greater focus on the general mathematical competencies in physics education.

\section{Mathematical competence in physics}

Tuminaro (2004) argued that the reasons why students struggle with mathematics in physics are: 1) students lack the prerequisite mathematical skills needed to solve problems in physics and/or 2) they do not know how to apply them to physics problems. Previous research within mathematics in physics education seems to be divided along these two groups of difficulties. Studies within the first group often explore correlations between mathematical skills and success in physics achievement (e.g., Buick, 2007; Halloun \& Hestenes, 1985; Hudson \& Liberman, 1982; Knight, 1995; Lawrenz et al., 2009; Meltzer, 2002; Sadler \& Tai, 2001). For instance, Meltzer (2002) studied the correlation between learning gains in physics and mathematical skills. His study suggested that students' initial mathematical skills had a significant impact on their learning gains in physics, while their initial level of physics concept knowledge was unrelated to their learning gains.

The second main group of studies within research on mathematics in physics education goes deeper into the causes of students' difficulties with the application of mathematics (Bing \& Redish, 2009; De Lozano \& Cardenas, 2002; Planinic, Milin-Sipus, Katic, Susac, \& Ivanjek, 2012; Rebello et al., 2007; Redish, 2006; B.L. Sherin, 2001; Torigoe, 2008; Tuminaro, 2004; Tuminaro \& Redish, 2007). These studies often focus on the problem of transfer where the 'translation' from the physics concept to the formalized language of mathematics represents a great challenge for physics students. Torigoe (2008) demonstrated that students struggle with problems in physics containing algebraic representations, and found that difficulties associated with symbolic physics questions were more pronounced for the students most likely to fail physics. Using cognitive load theory, he discussed how symbolic versions demanded a higher load of cognitive resources than numeric versions of the same problem.

However, neither the correlation studies nor the studies related to transfer include different nations or longitudinal perspectives that could illuminate the negative trend of declining achievements and interest in physics education. In 
addition none of these studies investigate empirically which mathematical competencies are pertinent for physics competence.

This indicates a need for other types of studies like large-scale, cross-national trend studies on the mathematical competencies pertinent for physics achievement. In the present study, we address this need and aim to explore the importance of mathematics for physics achievement and the most pertinent mathematical competencies in physics, using trend data from the large scale international trend survey TIMSS (Trends in Mathematics and Science Study) Advanced 1995 and 2008 in which four countries participated in both cycles (Slovenia, Russia, Norway and Sweden). We address this aim in the following research questions:

1. What is the difference between performances on physics items requiring mathematics as compared to not requiring mathematics for Slovenian, Russian, Norwegian and Swedish students and how have these performances developed during the 1995 to 2008 period?

2. What is the difference between performances on physics items that require different types of mathematical competencies pertinent to physics for Slovenian, Russian, Norwegian and Swedish students and how have these performances developed during the 1995 to 2008 period?

\section{Theoretical Framework}

We need a framework describing different types of mathematical competencies pertinent in physics in order to calculate performances on physics items requiring such competencies. Since no such framework exists (to our knowledge), we hence synthesize theories from mathematics and physics education.

\section{Mathematical competence}

There has been an increasing emphasis on mathematical competence rather than theoretical knowledge within research on mathematics education (Kilpatrick, Swafford, \& Findell, 2001). Mathematical competence is a broad notion, and involves factual knowledge, skills, and understanding, as well as the ability to use mathematics in contexts and situations in which mathematics plays a role (Niss 2003). This is in line with the general conception of competence in educational research, which is perceived to be a cluster of knowledge, skills and understanding "...which represents the ability to cope with complex, unpredictable situations.” (Westera, 2001, p. 6).

The KOM Project headed by Mogens Niss was initiated by the Ministry of Education in Denmark, who commissioned the development of a framework for 
mathematics competencies that could be implemented in upper secondary schools (Niss, 2003). The idea of this project was to build the curriculum on the concept of mathematics competence. Niss and his colleagues developed a framework that is divided into two main groups of mathematical competencies. The first group of competencies relates to the ability to ask and answer questions in and with mathematics and includes; thinking mathematically; posing and solving mathematical problems; modeling mathematically; and reasoning mathematically. The second group of competencies addresses the ability to manage mathematical tools and language. These include representing mathematical entities; handling mathematical symbols; communicating in, with, and about mathematics; and making use of aids (such as a calculator) (see Niss 2003 for details). The emphasis of mathematical tools in this second group of competencies is particularly relevant to the present study.

Although the competencies within both groups may overlap a bit in terms of required abilities, each competency maintains a unique major focus, a distinct “centre of gravity” (Niss, 2003, p. 9).

\section{Physics competence}

Dolin (2002) has constructed a framework for physics competence that intentionally parallels the set of competencies by Niss (2003) in the KOM project. Similar to the KOM framework, Dolin's physics framework targets the general competencies that are needed for understanding, communicating, and solving problems across all content knowledge within the given subject area. Both Dolin's and Niss' frameworks presuppose attitudes, subject content knowledge and knowledge about the nature of the subject (Dolin, 2002; Niss, 2003). A short summary of the physics framework is provided in Table 1 (lefthand column). This table presents a mapping of key relevant mathematical competencies within Niss' framework (right hand side) onto Dolin's framework of physics competencies. 
Table 1. Niss' mathematical competencies (right-hand side) required for physics competence (left-hand side)

\begin{tabular}{|l|l|}
\hline Physics competencies (Dolin, 2002) & $\begin{array}{l}\text { Relevant mathematical competencies (Niss, } \\
\text { 2003) }\end{array}$ \\
\hline $\begin{array}{l}\text { 1) perform physics thinking and reasoning } \\
\text { (such as: identifying and preparing key concepts } \\
\text { in order to solve tasks, asking relevant } \\
\text { questions, handling concepts, numbers, and } \\
\text { units and linking them to phenomena, } \\
\text { understanding and using symbols and equations, } \\
\text { following physics discourse, and deriving } \\
\text { formulas) }\end{array}$ & Handling symbols, mathematical modeling \\
\hline $\begin{array}{l}\text { 2) plan, perform and describe experiments } \\
\text { (and use equipment, determine the reliability } \\
\text { and uncertainty of results, and understand the } \\
\text { relation between theory and experiment) }\end{array}$ & handling symbols, mathematical modeling and \\
\hline $\begin{array}{l}\text { 3) build and analyze models } \\
\text { (Describe a physics problem and choose the } \\
\text { relevant variables, and create a mathematical } \\
\text { model that describes the problem) }\end{array}$ & handling of mathematical representations \\
\hline $\begin{array}{l}\text { 4) work with different representations of the } \\
\text { same phenomenon } \\
\text { (understand, use, and/or switch between } \\
\text { representations such as graphs, pictures, and } \\
\text { experiments) }\end{array}$ & handling mathematical representations \\
\hline $\begin{array}{l}\text { 5) communicate in, with, and about physics } \\
\text { (search for and use information about concepts, } \\
\text { units, and numbers in tables, databases, etc, } \\
\text { solve and evaluate problems of a more general } \\
\text { scientific and technical nature, and } \\
\text { communicate physics discourse }\end{array}$ & handling symbols, mathematical modeling and \\
\hline
\end{tabular}

We aimed to identify each of Niss' mathematical competencies in the physics framework of Dolin, so that the types of mathematical competencies identified in Dolin's framework would describe those pertinent in physics only. The types of mathematics competencies not identified in Dolin's framework are thus important in mathematics only.

To exemplify, Dolin's fourth competency, work with different representations of the same phenomenon, involves the students' abilities to shift between different representations such as graphs, pictures, verbal phrases and experiments, depending on the task and the variables involved. While physics is comprised of a wide variety of representations (Angell, C., Bungum, B., Henriksen, E.K., Kolstø, S.D., Persson, J., Renstrøm, R., 2011), according to Niss (2003), mathematical representations specifically refer to graphs, vectors, numerical equations, and the like, Niss' (2003) mathematical competency, representing mathematical entities, is hence integrated into Dolin's fourth competency. Thus, handling representations seem to be a competency required in mathematics and more importantly, also in physics.

Regarding Dolin's second competency (plan, perform and describe experiments), when a student is working with an experiment, he or she often has 
to produce a model of the reality in the language of mathematics and thus perform mathematical modelling. Furthermore, upon writing the journal for the experiment, a student may encounter formulas which need manipulation or equations to be solved. Hence for this component of physics competence the student is required to handle symbols. Moreover, experiments often involve mathematical representations such as graphs.

There are however, competencies that are specifically required in mathematics but not in physics. For instance within Niss' first competency (out of eight) called "thinking mathematically", he describes how student's abilities related to thinking mathematically involves: "distinguishing between different kinds of mathematical statements (including conditioned assertions ('if-then'), quantifier laden statements, assumptions, definitions, theorems, conjectures, cases)". This is more typical of the subject mathematics than physics. One may, of course, always argue that all sorts of mathematical competencies are important in physics; however, we tried to identify the ones most common and most pertinent in physics in upper secondary.

After having analyzed each of Dolin's five competencies we identified the most prominent mathematical competencies required in physics education. These are handling symbols, mathematical modeling, and handling mathematical representations.

Handling Symbols includes the following abilities: 1) decode and interpret formal mathematical language and understand its relations to everyday language; 2) translate from everyday language to formal mathematical language; and 3) handle and manipulate formulae and equations.

Mathematical modeling (in a physics context) is defined as student's ability to create a mathematical description of the physical world by arriving at the relationship between the variables. The student is not presented with a formula or a graph but rather derives these independently based on the presented variables.

Handling mathematical representations, involves the ability to utilize, understand, and shift between, for instance, symbols, functions, diagrams, graphs, and vectors. 


\section{A model of physics competence}

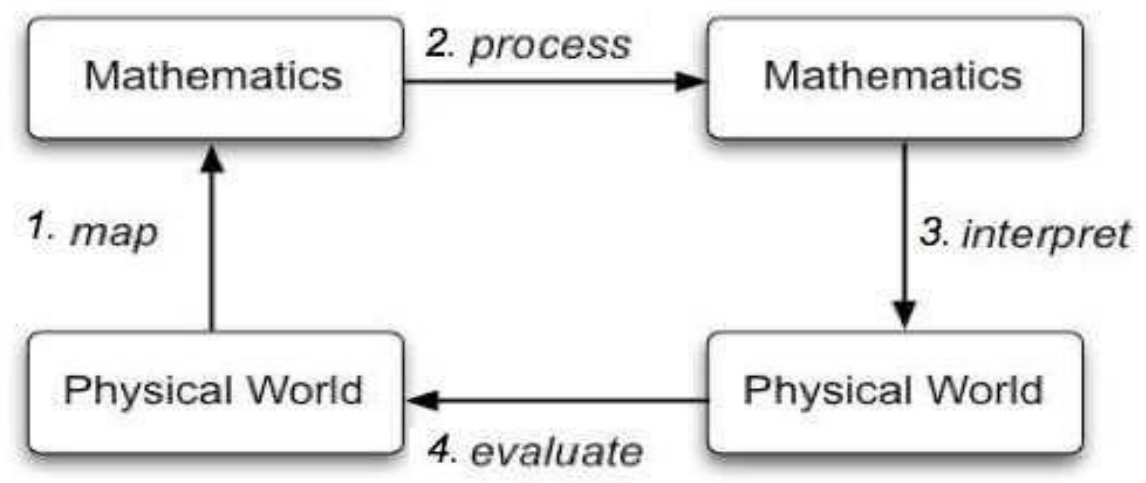

Figure 1. A model describing the transfer of knowledge between physics and mathematics

Bing and Redish (2009) applied a cognitive framework, building primarily on the work of DiSessa (1993), and built a model describing the transfer of knowledge between mathematics and physics (see Figure 1). They argued that students operate in different modes (e.g. physics or mathematics mode) or what they call frames, and the model describes how a student start in the mode of physics where the physical system needs to be described. Then the student enters into the mode of mathematics where mathematical operations and manipulations are performed. The result has to be interpreted in the physical world where the student is in a mode of physics and then validated according to the problem statement. This model is useful, but does not, however, describe what types of mathematics is required. We hence build our model on Redish and Bings (2009) cognitive framework, but extend the part of the model concerned with mathematics so as to include the different types of mathematical competencies required in physics.

The three mathematical competencies highlighted in the previous section, handling symbols, mathematical modeling, and handling mathematical representations, contribute to only a portion of physics competence, which involves more than mathematical abilities (like conceptual understanding).

Within the larger context of physics and mathematics competence, the three applied mathematical competencies in physics are highlighted in Figure 2. This figure displays a model of physics competence required in physics-related tasks in secondary school and clarifies the relationship between the cognitive domain of physics and the cognitive domain of of mathematics. The cognitive domain, in this sense, directly refers to the context in which tasks are solved and hence a type of cognitive mode (Erickson, 2006; Bing \& Redish, 2009). For example, if a student is working on a task in physics, (s)he is enacting schematic language and conceptual knowledge in order to successfully complete this task that is embedded in a physics context (e.g., experiments, classroom, books, etc.). 


\section{The Cognitive domain of physics}

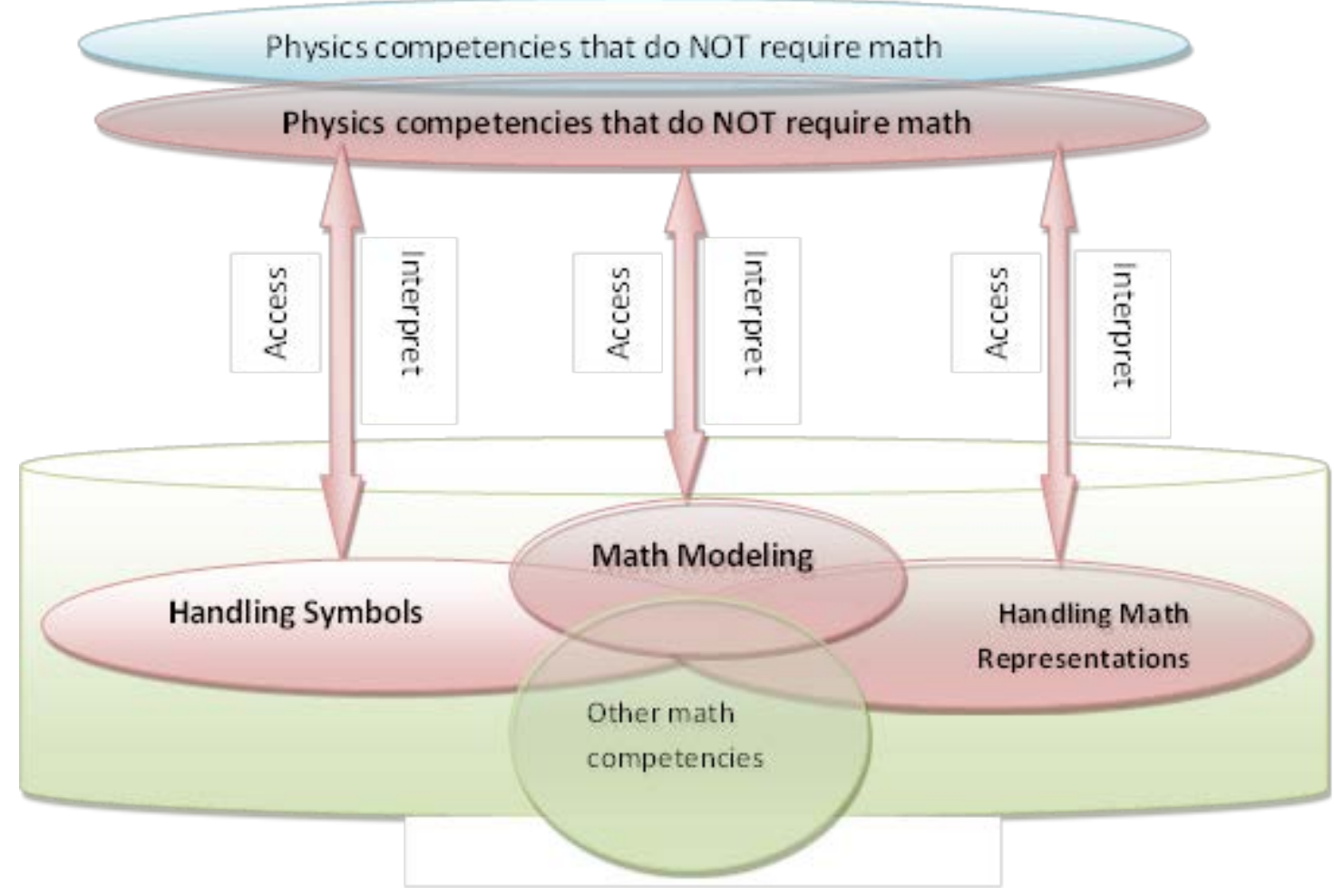

The Cognitive domain of mathematics

Figure 2. A model of the relationship between physics competence and the most pertinent types of mathematics competencies required to solve physics tasks in upper secondary school.

The top cylinder in Figure 2 illustrates the cognitive domain of physics. This domain may include two groups of physics competencies, those that require mathematics and those that do not. The physics competencies represented in the ovals directly refer to the physics competencies previously described in Table 1 . The physics competencies that require mathematical abilities are linked to mathematical competencies which were also described in Table 1 . Within the cylindrical boundary of the physics domain, non-cognitive factors (e.g., attitude, motivation, and self-efficacy) are also present and influence physics competence; however, these affective considerations are superfluous to the scope and purpose of the present study and thus will not be highlighted in this model.

The lower cylinder in Figure 2 represents the cognitive domain of mathematics. Three of the four ovals inside this cylinder represent the mathematical competencies most pertinent to physics; Handling Symbols, Mathematical Modeling, and Handling Mathematical Representations.

The fourth oval represents mathematical competencies that are solely relevant to the subject of mathematics. Similar to the domain of physics, the 
domain of mathematics also includes non-cognitive factors, which, again, are beyond the scope of this study.

In order to achieve the necessary physics competence required on a physics task, a student may have to move between the modes of mathematics and physics. Although the physics task may be quite mathematical in nature (e.g., the creation of, or reference to, a mathematical representation such as a graph), physics is still the dominant mode in the beginning and at the end of the given task. First, various elements such as concepts, units, or numbers have to be linked to a physics phenomenon in order to determine the key elements that characterize the system that describes this phenomenon. Then the student has to switch to the cognitive mode of mathematics in order to access mathematical competencies. For example, the competency Handling Symbols is accessed in order to successfully manipulate and solve an equation. When performing mathematical operations, the student thinks and acts in the mode of mathematics (Erickson, 2006). Subsequently, re-entering the mode of physics is necessary in order to interpret the answer and then to communicate and evaluate the answer in a physics context.

Our model is developed for two purposes, to contribute to theory within the field of mathematics in physics education, and to serve as a framework for our methodology.

\section{Method}

We employed the theoretical framework previously described and illustrated in Figure 2 to categorize the physics items from both 1995 and 2008 TIMSS Advanced surveys. We then calculated achievements (defined in terms of mean percentage of correct answers) for these categories. Finally, we compared the achievements on these categories across time (1995 and 2008) and nations.

\section{TIMSS}

The TIMSS Advanced survey (in 1995 and 2008) examines students' performance in advanced mathematics and physics in the last year of upper secondary school. In order to compare countries and investigate trends from 1995 to 2008, the mean achievements of all countries were standardized according to an International Average, which was set on a mean scale of 500 with a SD of 100 (Mullis, Martin, Robitaille, \& Foy, 2009). This was done by an IRT-model (item response theory), and the performance in 1995 was recalculated to fit the model used in 2008 (Foy, Galia, \& Li, 2009). This could be done because approximately half of the items from TIMSS Advanced 1995 were not publically released and were reused in 2008 in order to allow for trend analysis. Such items are called trend items. 
The frameworks of TIMSS and TIMSS Advanced are developed on the basis of all the participating countries' curricula, which include a content dimension and a cognitive dimension: knowing, applying, and reasoning (Mullis et al., 2009). This latter dimension strongly resembles our earlier definition of competence (a cluster of knowledge and skills and how to apply these in complex contexts), and so one may argue that physics achievement in TIMSS Advanced is a measurement of important aspects of physics competence. In order to ensure validity, an extensive number of items are created, both multiple choice (MC) items and open-ended, or constructed response items (CR). In 1995, there were $42 \mathrm{MC}$ and $23 \mathrm{CR}$ items (65 items in total), and in the 2008 iteration there were $44 \mathrm{MC}$ and $29 \mathrm{CR}$ items (73 items in total) (Mullis et al., 2009).

All TIMSS and TIMSS Advanced surveys also examine contextual sociocultural factors by including student, teacher, and school questionnaires, and all countries have to supply information about their curricula, educational policies, and demographics (Mullis et al., 2009).

\section{Participants}

Our sample included participants from the TIMSS Advanced 1995 and 2008 iterations $(\mathrm{N}=11524)$. This sample included students from Slovenia, Russia, Norway, and Sweden in their last year of upper secondary school (12th grade). Only students from these four countries participated in both iterations of TIMSS Advanced (Mullis et al., 2009). Table 2 presents the by-country total number and age of participants as well as the proportion of the age cohort covered by the test population (called PCI - Physics Coverage Index) across the two iterations. The large drop in PCI for Slovenia is due to a curricular reform, where, different to 1995, physics was not anymore compulsory in 2008 (Office, 2013).

Table 2. A description of the TIMSS Advanced samples in 1995 and 2008

\begin{tabular}{|llll|}
\hline Country & Sample & Age & PCl (\%) \\
& $\mathbf{1 9 9 5 / 2 0 0 8}$ & $\mathbf{1 9 9 5 / 2 0 0 8}$ & $\mathbf{1 9 9 5 / 2 0 0 8}$ \\
\hline Slovenia & $512 / 1120$ & $18.8 / 18.7$ & $39.0 / 7.5$ \\
\hline Russia & $985 / 3166$ & $16.9 / 17.1$ & $2.0 / 2.6$ \\
\hline Norway & $1048 / 1642$ & $19.0 / 18.8$ & $8.0 / 6.8$ \\
\hline Sweden & $760 / 2291$ & $18.9 / 18.8$ & $16.0 / 11.0$ \\
\hline
\end{tabular}

\section{Item Categorization}

As part of the TIMSS Advanced project, we have access to both released and non-released items and were able to include them all in the categorization. We employed our framework (illustrated in Figure 2) to create a coding scheme for categorizing the TIMSS Advanced physics items for the 1995 and 2008 iterations. 
The physics items in both surveys were first coded according to the following two categories: Math and No Math. Thus, an item was coded as Math if the student has to use, find, or identify a formula and/or if the item explicitly contains mathematical representations such as graphs, vectors, or equations. All other items were categorized as No math.

The items coded as Math were further categorized into Handling Symbols, Mathematical Modeling, and Handling Mathematical Representations in accordance with our model described previously. An item was coded as Handling Symbols if the student is required to manipulate a formula, solve an equation, or plug numbers into an equation. Similarly, an item was coded as Handling Mathematical Representations if the student is required to shift between, understand, or use graphs or vectors (e.g., arrows representing acceleration). Items related to Mathematical Modeling would include tasks in which the student would have to arrive at a formula or relation between concepts.

Our coding process was carried out in two cycles. During the first cycle, one physicist and two mathematicians separately categorized all the items from the two test iterations. These three researchers then discussed and resolved any disagreements. The coding scheme was given to two additional researchers (a mathematician and a physicist) who performed a second cycle of coding. A group involving the two researchers from the second cycle and the physicist from the first cycle discussed any further disagreements with the assigned categories. The inter-rater reliability (IRR) (Fleiss' kappa; for details, see Fleiss, Cohen, \& Everitt, 1969) for the two cycles of coding was 0.61 and 0.79 , respectively.

We will now exemplify some of the items that caused disagreement among the coders, and describe how these issues were solved. An item was coded as Handling Symbols if the student is required to manipulate a formula, solve an equation, or plug numbers into an equation. This latter requirement of plugging numbers into equations was added to the coding scheme after the first cycle of coding, due to disagreement regarding items such as this:

A stone is dropped from rest down a deep well. It takes $2 \mathrm{~s}$ to reach the bottom.

How deep is the well?

Assume that the air resistance on the falling stone is negligible and that the acceleration due to gravity $\mathrm{g}=9.8 \mathrm{~m} / \mathrm{s} 2$.

a) $4.9 \mathrm{~m}$, b) $9.8 \mathrm{~m}$, c) $19.6 \mathrm{~m}$, d) $39.2 \mathrm{~m}$, e) $78.4 \mathrm{~m}$

The students were provided with a formula sheet, and so in this item they could just plug the numbers into the formula and find the answer $(19.6 \mathrm{~m})$. Although the student is not required to manipulate formula as such in this item, according 
to Niss (2003), handling symbols also includes handling mathematical expressions and formula. We hence included items like this in the category Handling symbols.

Sometimes, an item required more than one competency, like the item described below that requires both Handling Mathematical Representations and Handling Symbols.

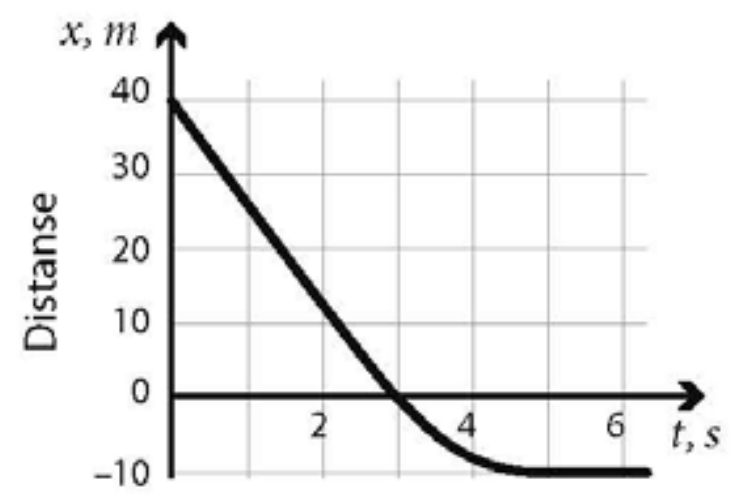

The graph above represents a cyclist approaching and passing the finishing line in a race. If the cyclist weighs $60 \mathrm{~kg}$, what is her momentum as she crosses the finishing line?

$2400 \mathrm{~kg} \mathrm{~m} / \mathrm{s}$, b) $800 \mathrm{~kg} \mathrm{~m} / \mathrm{s}, \mathrm{c}) 600 \mathrm{~kg} \mathrm{~m} / \mathrm{s}$, d) $0 \mathrm{~kg} \mathrm{~m} / \mathrm{s}$

In this item, the student has to use the graph to find the velocity, and then plug this number into the formula for momentum. This item hence requires the student to use a mathematical representation (i.e. the graph), and to handle symbols by making use of the formula for momentum. After the first cycle of coding, where items like this were coded differently, we agreed to focus on the main competency required, or the competency that required the highest level of cognition. In this item, the main requirement involves the ability to understand a graph, and to read the slope of a graph to find the velocity. Multiplying the velocity with the weight is less demanding and is not the main issue at hand. This item was hence coded as Handling Mathematical Representations.

\section{Calculating Student Responses}

Student responses for TIMSS Advanced physics items were calculated in the form of $p$-values, which are the percentage of students with a correct answer within the context of this study. For two points items, partially correct answers are weighted by a factor of 0.5 . We calculated the $p$-value for each item, then the mean $p$-values for all the competency categories previously described and then the international average was subtracted from each of these mean $p$-values. 
Thus, a negative $p$-value in a category means that the students performed below international average on items within this category.

Caution is required when comparing $p$-values. There were countries who participated in 1995 that did not participate in 2008 and vice versa. Hence, the two international averages are not directly comparable. However, about half the items (called trend items) were the same across the two surveys. In order to enhance reliability and validity, we also calculated $p$-values based entirely on the trend items. The results from the analysis of trend items only, were compared with the analysis of all items.

\section{Results}

\section{Students' Performance on Physics Items}

Achievements, or mean $p$-values relative to the international average for the categories Math and No math are provided in Table 3 along with the number of items in each category. The table also provides the differences in each country's achievement in 2008 relative to 1995 within one category.

\begin{tabular}{|c|c|c|c|c|c|c|c|c|c|c|c|c|c|c|}
\hline & \multicolumn{2}{|c|}{ No. of items } & \multicolumn{3}{|c|}{ Norway } & \multicolumn{3}{|c|}{ Sweden } & \multicolumn{3}{|c|}{ Slovenia } & \multicolumn{3}{|c|}{ Russia } \\
\hline & 1995 & 2008 & 1995 & 2008 & $\begin{array}{l}2008- \\
1995\end{array}$ & 1995 & 2008 & $\begin{array}{c}2008- \\
1995\end{array}$ & 1995 & 2008 & $\begin{array}{l}2008- \\
1995\end{array}$ & 1995 & 2008 & $\begin{array}{l}2008- \\
1995 \\
\end{array}$ \\
\hline Math & 42 & 33 & 14 & 1 & $-13^{*}$ & 14 & -4 & $-18^{*}$ & 8 & 7 & -1 & 7 & 4 & -3 \\
\hline $\begin{array}{l}\text { No } \\
\text { math }\end{array}$ & 29 & 35 & 11 & 9 & -2 & 7 & 3 & -4 & 5 & 2 & -3 & 6 & 2 & -4 \\
\hline
\end{tabular}

Table 3. Students' achievements relative to the international average on the two categories of physics items: Math and No Math in 1995 and 2008. * indicates a significant difference at the .05 level

All the calculated $p$-values in tables 3 and 4 have standard error (SE) less than 3 percentage points (Lie, Angell, \& Rohatgi, 2010). This means that if the differences between the years 2008 and 1995 are above 5.9 (=1.96 times SE) percentage points then the difference is significant.

For Norway, there was a statistically significant decrease between 2008 and 1995 on math related items, with a percentage-point difference of 13. Similarly, there was a significant decrease between the two testing cycles for Sweden, which had a percentage-point difference of 18. Thus, Norway and Sweden's achievements on items requiring mathematics declined significantly from 1995 to 2008, even though there were more items in the category Math in 1995 as compared with 2008. Further, in 1995 all countries scored better on items requiring Math than No math (however only Sweden significantly). In 2008 however, Norwegian and Swedish students performed lower on items requiring 
mathematics. There were no other significant findings from this portion of the analysis.

In order to ensure reliability and validity, we performed the same type of analysis on trend items only. The results from this analysis supported our results (presented in Table 3) as the same profiles appeared (i.e., the large and significant decline on items requiring mathematics for Norway and Sweden, and no significant findings for Russia and Slovenia).

\section{Students' Performance on Physics Items Requiring Mathematics}

Table 4 presents the results of our coding of math-related physics items and the reported achievement on the subtotals of these categorized items. No items were coded as relating to the competency Mathematical Modeling. Thus, Mathematical Modeling, as defined in this study, was not present in the TIMSS Advanced physics items for the two testing iterations.

\begin{tabular}{|c|c|c|c|c|c|c|c|c|c|c|c|c|c|c|}
\hline & \multicolumn{2}{|c|}{$\begin{array}{l}\text { No. of } \\
\text { items }\end{array}$} & \multicolumn{3}{|c|}{ Norway } & \multicolumn{3}{|c|}{ Sweden } & \multicolumn{3}{|c|}{ Slovenia } & \multicolumn{3}{|c|}{ Russia } \\
\hline & $\begin{array}{c}199 \\
5 \\
\end{array}$ & $\begin{array}{c}200 \\
8 \\
\end{array}$ & 1995 & 2008 & $\begin{array}{l}2008- \\
1995 \\
\end{array}$ & 1995 & 2008 & $\begin{array}{l}2008- \\
1995 \\
\end{array}$ & 1995 & 2008 & $\begin{array}{c}2008 \\
- \\
1995 \\
\end{array}$ & 1995 & 2008 & $\begin{array}{c}2008 \\
- \\
1995 \\
\end{array}$ \\
\hline $\begin{array}{l}\text { Handling } \\
\text { Symbols }\end{array}$ & 26 & 24 & 15.4 & 0.0 & $-15.4^{*}$ & 15.3 & -4.6 & $-19.9^{*}$ & 6.8 & 7.0 & 0.2 & 9.5 & 4.9 & -4.6 \\
\hline $\begin{array}{l}\text { Handling Math. } \\
\text { Representation } \\
\text { s }\end{array}$ & 16 & 9 & 10.6 & 3.5 & -7.1 & 6.5 & -2.2 & -8.7 & 9.0 & 6.3 & -2.7 & 3.0 & 2.4 & -0.6 \\
\hline
\end{tabular}

Table 4. Students' achievements on the two categories handling symbols and handling mathematical representations in 1995 and in 2008 relative to the international average.*indicates a significant difference at the .05 level

Performance on items categorized as Handling Symbols declined significantly among Norwegian respondents (15 percentage points) and Swedish respondents (20 percentage points) over the two iterations. Performance on items categorized as Handling Mathematical Representations declined significantly among only Swedish respondents (9 percentage points) over the two iterations. There were no other significant effects from this portion of the analysis. The same results appeared from the analysis of the trend items only.

\section{Discussion}

\section{Empirical results}

According to the International Report of TIMSS Advanced 2008, Norway and Sweden used to be top performing countries in physics in 1995 and were also the two countries with the largest decline in overall physics achievement between 1995 and 2008 (Mullis et al., 2009). There were no significant changes in the overall physics achievement during this time span for Russia and Slovenia (ibid). 
Our main findings show that a large number of the physics items require mathematics, especially the competency Handling Symbols. Norwegian and Swedish students' performance on these items declined significantly during this time span. This suggests that the main reason for Norway and Sweden's overall physics decline could have been due to poor mathematical competence, especially the competency Handling Symbols. This is in line with the Norwegian report (Lie et al., 2010) and the Swedish report (Skolverket, 2009) from TIMSS Advanced. Other possible reasons for the decline have been studied in an analysis conducted by Lie, Angell \& Rohatgi (2012). It showed that changes in contextual and background variables (such as home background, instruction, and school environment) had had little influence on changes in physics achievement between 1995 and 2008.

Hence, our results, seen in light of previous studies, indicate that mathematical competence may be of great importance to students' physics achievement and that the most important competency (at least in the TIMSS physics context) could be that which requires students to handle symbols.

In order to address our main aim of exploring the role of mathematics in physics in depth, we now turn the focus to possible reasons why our Nordic students' struggle with physics items requiring mathematics. Difficulties with mathematics in physics could be related to 1) the prerequisite mathematical competencies required in physics and/or 2) struggles with transfer between mathematics and physics. Our model is an important frame of reference for this discussion.

\section{The prerequisite mathematical competencies of physics}

Our definition of the category handling symbols in the model is quite similar to the description of algebra in the TIMSS 2003 mathematics framework for grade 8 (Mullis et al., 2003). They overlap in the sense that they both describe basic algebraic skills, such as manipulating equations. Hence, the basic algebra taught in lower secondary school is a prerequisite skill for physics competence in upper secondary school. To this end, it could be appropriate to seek explanations for the Norwegian and Swedish physics students' difficulties with physics items categorized as handling symbols in results from TIMSS 2003 Mathematics for eight graders. This may be especially relevant since the population tested in TIMSS Advanced in 2008 is the same age cohort that was tested in grade 8 in TIMSS 2003 five years earlier in Norway and Sweden (Mullis, Martin, Gonzalez, \& Chrostowski, 2004; Mullis et al., 2009). In TIMSS 2003, Norwegian and Swedish eighth graders performed significantly lower than in TIMSS 1995 in mathematics, a decline larger than most countries (Mullis et al., 2004). Furthermore, they performed low on items in algebra compared with other content areas in mathematics, and compared to Slovenia and Russia. In conclusion, these four countries' performance on algebra items in TIMSS 2003 Mathematics could hence be related to their performance in TIMSS Advanced 
2008 on physics items categorized as handling symbols. Findings from secondary analysis of PISA 2003 support findings from TIMSS 2003: the Nordic cluster of participating countries struggled the most with algebra in mathematics, as compared with the Central Eastern European cluster, which performed well on algebra (Olsen \& Grønmo, 2006).

Research within the field of mathematics education indicates that students from a number of western countries struggle with algebra (e.g., Brandell, Hemmi, \& Thunberg, 2008) which in turn could be related to an extensive Mathematics Reform (ibid). The ideas of this reform started in America in the 1980s and turned the focus from a traditional strong symbolic orientation with emphasis on formal methods, to a reformist algebra with an emphasis on solution of "real-world" problems (Kieran, 1992). These changes seem to have affected mathematics as a school subject also in Norway and Sweden from the mid 1990s. For instance, "Mathematics in daily life" was one of the main goals in the mathematics curriculum of 1997 both for primary and lower secondary Norwegian schools (KUF, 1996). The emphasis on "real-world" problems seems to have been made at the expense of more formal mathematics, which often involves drill and training, and this may imply that Norwegian students do not develop the necessary fluency in handling algebraic symbols (Grønmo \& Onstad, 2009; Grønmo, Onstad, \& Pedersen, 2010). Also in Sweden, the focus in mathematics has been on realistic contexts with examples from everyday life (Brandell et al., 2008). The focus on real-world problems in the Norwegian and Swedish curricula is reflected in findings from a study using data from PISA 2003, where Nordic countries performed better on items with realistic contexts than the Central Eastern European cluster (Olsen \& Grønmo, 2006).

In addition to the basic mathematics taught in lower secondary, the mathematics taught in upper secondary school may also influence physics competence. The Slovenian and Russian mathematics curricula in upper secondary school (Mullis et al., 2009) seem to have been less touched by the Mathematics Reform compared to Norway and Sweden. The extensive and advanced algebra in the Russian and Slovenian mathematics curricula remained almost unaltered from 1995 to 2008 (Mullis et al., 1998; Mullis et al., 2009). Furthermore, in 2008 Slovenian participants enrolled in four years of compulsory advanced mathematics while Norwegian and Russian participants only had two years and Swedish participants three years (Mullis et al., 2009). Russian students also had twice the amount of hours with advanced mathematics per year compared to the other three countries (ibid). In addition, the most advanced mathematics course was no longer obligatory for the Swedish physics students who participated in TIMSS Advanced 2008 as compared to 1995 (Skolverket, 2009). Hence, Russian and Slovenian students had more mathematics in 2008 than our Nordic countries, both in terms of hours of instruction per year and in terms of number of years. The number of mathematics classes taken has been shown to have a positive relationship with 
physics achievement in upper secondary (Lawrenz et al., 2009; Norvilitis, Reid, \& Norvilitis, 2002).

\section{Struggles with transfer}

Students' difficulties with mathematics in physics may also be related to struggles with transfer between physics and mathematics. In our model (see Figure 2), physics competence is divided into two parts: physics competencies that do not require mathematics and physics competencies that do require mathematics. The latter require the students to move between the mode of physics and mathematics, and this is when problems with transfer may occur (Rebello, 2007; Angell, Kind, Henriksen, \& Guttersrud, 2008). For example, Rebello (2007) claimed that "...the main difficulty that students appear to have does not lie in their lack of understanding mathematics per se, rather it lies in their inability to see how mathematics is appropriately applied to physics problems” (p. 30). In a study by Angell et al. (2008), the physics students reported that the algebra required in physics in fact was simple, yet they could not perform simple manipulations of equations. Further, they failed to see the resemblance between the mathematical linear function $Y(x)=a x+b$ with the linear function for velocity $v(t)=v_{0}+a t$.

Torigoe (2008) argued that the symbolic language of algebra is especially demanding for students' cognition during transfer from mathematics to physics. It is plausible that this transfer is even more demanding for students that lack prerequisite algebraic fluency. When engaging in physics, a large part of our Nordic students' cognitive capacity could thus be preoccupied with basic algebra rather than the physics phenomenon under study.

In addition to prerequisite algebraic skills, the type of context presented for the students when they learn mathematics as a school subject is important. In 1995, physics was commonly used as a context for applied mathematics in Norway and Sweden (Skolverket, 2009; UDIR, 1996). Also, the Swedish TIMSS Advanced reports argue that there was less focus on physics examples in the mathematics curricula for the participants in 2008 as compared to 1995 (Skolverket, 2009). When students are unfamiliar with a physics context in mathematics, it could make transfer in physics harder.

One may ask though whether the responsibility of making the transfer easier rests on mathematics only. Mulhall and Gunstone (2008) have pointed out that physics teachers pay little attention to the place of mathematics in physics, and Reddish (2006) claimed that physics teachers should take a greater responsibility and teach students how to apply mathematics in physics. Moreover, Uhden et al. (2011) claimed that "the knowledge about a supportive use of mathematics in physics education is still fragmentary" (p. 2) within research in physics education.

To this end, further research on how to incorporate and apply mathematics in physics is needed. 


\section{Contributions and Implications}

Our study contributes to the interdisciplinary field of mathematics and physics in three ways. First, we have developed a model for the interrelation between physics and mathematics, which may be helpful in further research within this field. Second, we have based our theories and empirical findings on theories of competence (rather than knowledge or skills) (Westera, 2001). And third, our results indicate that mathematical competence could be related to physics performance and that the mathematical competency most pertinent to physics performance (as measured in TIMSS Advanced) may be that which requires students to handle symbols.

In order to account for the role of mathematics in physics, there seems to be a need to focus on traditional algebra and physics contexts in the mathematics curricula in lower secondary. Furthermore, in upper secondary, physics could gain from a greater emphasis on how to apply mathematics, in physics. In general, we suggest that it might be time to balance the focus in mathematics between traditional algebra and everyday mathematics and the focus in physics between quantitative approaches ( that require mathematical competencies) and qualitative (that do not require mathematical competencies). The interconnection between mathematics and physics in secondary school needs strengthening, and this is important for the future generation to be able to enroll in the much-needed STEM (Science, Technology, Engineering and Mathematics) subjects.

\section{References}

Anderson, J. (1976). Language, memory, and thought, Hillsdale, N.J: Erlbaum.

Angell, C., Bungum, B., Henriksen, E.K., Kolstø, S.D., Persson, J., Renstrøm, R. (2011). Fysikkdidaktikk. Oslo: Høyskoleforlaget A/S

Angell, C., Guttersrud, O., Henriksen, E. K., \& Isnes, A. (2004). Physic: Frightful, but fun. Pupils' and teachers' views of physics and physics teaching. Science Education, 88(5), 683-706.

Angell, C., Kind, P. M., Henriksen, E. K., \& Guttersrud, Ø. (2008). An empiricalmathematical modelling approach to upper secondary physics. Physics Education, 43(3), 256.

Bing, T. J., \& Redish, E. F. (2009). Analyzing problem solving using math in physics: Epistemological framing via warrants. Physical Review Special Topics-Physics Education Research, 5(2), 020108.

Brandell, G., Hemmi, K., \& Thunberg, H. (2008). The widening gap - a Swedish perspective. Mathematics Education Research Journal, 20(2), 38-56.

Buick, J. (2007). Investigating the correlation between mathematical pre-knowledge and learning gains in service physics. European Journal of Physics, 28, 1073.

Carlone, H. B. (2003). Innovative science within and against a culture of "Achievement". Science Education, 87(3), 307- 328.

Croft, A. C., Harrison, M. C., \& Robinson, C. L. (2009). Recruitment and retention of students-an integrated and holistic vision of mathematics support. International Journal of Mathematical Education in Science and Technology, 40(1), 109-125. 
De Jong, O. (2004). Curriculum Reform and New Practices in Classrooms and Teacher Courses. International Journal of Science and Mathematics Education, 2(4), 431-434. doi: 10.1007/s10763-005-0715-8

De Lozano, S. R., \& Cardenas, M. (2002). Some Learning Problems Concerning the Use of Symbolic Language in Physics. Science \& Education, 11(6), 589-599. doi: 10.1023/a:1019643420896

deLange, J. (1996). Using and applying mathematics in education. In K. C. A. J. Bishop, C. Keitel, J. Kilpatrick, \& C. Laborde (Ed.), International Handbook of Mathematics Education (Vol. 1): Dordrecht: Kluwer.

DiSessa, A. A. (1993). Toward an epistemology of physics. Cognition and instruction, 10(23), 105-225.

Dolin, J. (2002). Fysikfaget i forandring. Danish only) PhD thesis. Roskilde University, Denmark.

Duit, R., Niedderer, H., \& Schecker, H. (2007). Teaching physics. In S. K. Abell \& N. G. Lederman (Eds.), Handbook of research on science education (pp. 599-629). Mahwah: Lawrence Erlbaum Associates.

Duit, R., \& Treagust, D. F. (2012). Conceptual Change: Still a Powerful Framework for Improving the Practice of Science Instruction. In K. C. D. Tan \& M. Kim (Eds.), Issues and Challenges in Science Education Research (pp. 43-54): Springer Netherlands.

Erickson, T. (2006). Stealing from physics: modeling with mathematical functions in datarich contexts. Teaching mathematics and its applications, 25(1), 23 - 32.

Fleiss, J. L., Cohen, J., \& Everitt, B. (1969). Large sample standard errors of kappa and weighted kappa. Psychological Bulletin, 72(5), 323.

Foy, P., Galia, J., \& Li, I. (Eds.). (2009). Scaling the Data from the TIMSS Advanced 2008 Assessments. Chestnut Hill, MA: TIMSS \& PIRLS International Study Center, Boston College.

Gilbert, J. K. (2004). Models and Modelling: Routes to More Authentic Science Education. International Journal of Science and Mathematics Education, 2(2), 115-130. doi: 10.1007/s10763-004-3186-4

Grønmo, L. S., Onstad, T. (2009). Tegn til bedring. Norske elevers prestasjoner i matematikk og naturfag i TIMSS 2007. Oslo: Unipub.

Grønmo, L. S., Onstad, T. \& Pedersen, I.F. (2010). Matematikk i motvind. TIMSS Advanced 2008 i videregående skole. Oslo: Unipub.

Halloun, I. A., \& Hestenes, D. (1985). The initial knowledge state of college physics students. American journal of Physics, 53(11), 1043 -1055.

Halmos, P. (1985). Pure Thought Is Better Yet. College Mathematics Journal, 16(1), 14-16.

Hiebert, J., \& Lefevre, P. (1986). Conceptual and procedural knowledge in mathematics: An introductory analysis. Conceptual and procedural knowledge: The case of mathematics, $1-27$.

Hudson, H., \& Liberman, D. (1982). The combined effect of mathematics skills and formal operational reasoning on student performance in the general physics course. American journal of Physics, 50(12), 1117-1119.

Kelley, B., Hosp, J. L., \& Howell, K. W. (2008). Curriculum-Based Evaluation and Math An Overview. Assessment for Effective Intervention, 33(4), 250-256.

Kieran, C. (1992). The learning and teaching of school algebra. In D. A. Grous (Ed).Handbook of research on mathematics teaching and learning (pp.390-419) New York: Macmillan.

Kilpatrick, J., Swafford, J., \& Findell, B. (2001). Adding it up: Helping children learn mathematics. Washington DC: National Academies Press. 
Knight, R. D. (1995). The vector knowledge of beginning physics students. Physics Teacher, 33, 74-74.

KUF. (1996). Læreplanverket for den 10-årige grunnskolen. oslo: Gan Grafisk AS.

Lawrenz, F., Wood, N. B., Kirchhoff, A., Kim, N. K., \& Eisenkraft, A. (2009). Variables affecting physics achievement. Journal of Research in Science Teaching, 46(9), 961-976. doi: 10.1002/tea.20292

Lesh, R., Lesh, R., \& Landau, M. (1983). Acquisition of mathematics concepts and processes. Orlando, FL: Academic Press.

Lie, S., Angell, C., \& Rohatgi, A. (2010). Fysikk i fritt fall? Oslo: Unipub.

Lie, S., Angell, Carl, Rohatgi, Anubha. (2012). Interpreting the Norwegian and Swedish trend data for physics in the TIMSS Advanced Study. Nordic Studies in Education, 177-195.

Meltzer, D. E. (2002). The relationship between mathematics preparation and conceptual learning gains in physics: A possible "hidden variable" in diagnostic pretest scores. American journal of Physics, 70, 1259.

Mulder, M., Gulikers, J., Biemans, H., \& Wesselink, R. (2009). The new competence concept in higher education: error or enrichment? Journal of European Industrial Training, 33(8/9), 755-770.

Mulhall, P., \& Gunstone, R. (2008). Views about physics held by physics teachers with differing approaches to teaching physics. Research in Science Education, 38(4), 435-462.

Mullis, I. V. S., Martin, M. O., Beaton, A. E., Gonzalez, E. J., Kelly, D. L., \& Smith, T. A. (1998). Mathematics and Science Achievement in the Final Year of Secondary School: IEA's Third International Mathematics and Science Study (TIMSS). TIMSS International Study Center, Boston College, School of Education, Campion Hall, Chestnut Hill, MA.

Mullis, I. V. S., Martin, M. O., Gonzalez, E. J., \& Chrostowski, S. J. (2004). TIMSS 2003 International Mathematics Report. Findings From IEA's Trends in International Mathematics and Science Study at the Fourth and Eighth Grades. Chestnut Hill, MA: TIMSS \& PIRLS International Study Center, Boston College.

Mullis, I. V. S., Martin, M. O., Robitaille, D. F., \& Foy, P. (2009). TIMSS Advanced 2008 International Report. Boston: TIMSS \& PIRLS International Study Center.

Mullis, I. V. S., Martin, M. O., Smith, T. A., Garden, R. A., Gregory, K. D., Gonzalez, E. J., O`Connor, K. M. (2003). Assessment Frameworks and Specifications 2003. Boston: TIMSS \& PIRLS International Study Center, Boston College.

Niss, M. (2003). Mathematical competencies and the learning of mathematics: the Danish KOM project. Paper presented at the A. Gagatsis \& S. Papastavridis (Eds.), 3rd Mediterranean conference on mathematical education, New York.

Norvilitis, J. M., Reid, H. M., \& Norvilitis, B. M. (2002). Success in everyday physics: The role of personality and academic variables*. Journal of research in science teaching, 39(5), 394-409.

Office, G. C. (2013). from http://www.ukom.gov.si/en/media_relations/background_information/education/education al_system_in_slovenia/

Olsen, R. V., \& Grønmo, L. S. (2006). What are the Characteristics of the Nordic Profile in Mathematical Literacy? Northern Lights on PISA 2003: A Reflection from the Nordic Countries, 63.

Osborne, J., Collins, S. (2001). Pupils' views of the role and value of science curriculum: A focus-group study. International Journal of Science Education, 23(5), 441-468.

Osborne, J., \& Dillon, J. (2008). Science education in Europe: Critical reflections. London: Nuffield Foundation. 
Planinic, M., Milin-Sipus, Z., Katic, H., Susac, A., \& Ivanjek, L. (2012). Comparison of Student Understanding of Line Graph Slope in Physics and Mathematics. International Journal of Science and Mathematics Education, 1-22. doi: 10.1007/s10763-012-9344-1

Rebello, N. S., Cui, L., Bennett, A. G., Zollman, D. A., \& Ozimek, D. J. (2007). Transfer of learning in problem solving in the context of mathematics and physics. In D. H. Jonassen (Ed.), Learning to Solve Complex Scientific Problems. Mahwah, NJ: Lawrence Earlbaum.

Redish, E. F. (2006). Problem solving and the use of math in physics courses. Arxiv preprint physics $/ 0608268$.

Sadler, P. M., \& Tai, R. H. (2001). Success in introductory college physics: The role of high school preparation. Science Education, 85(2), 111-136.

Sfard, A. (1991). On the dual nature of mathematical conceptions: Reflections on processes and objects as different sides of the same coin. Educational Studies in Mathematics, 22(1), 1-36. doi: 10.1007/bf00302715

Sherin, B. L. (2001). How Students Understand Physics Equations. Cognition and Instruction, 19(4), 479 - 541.

Sherin, B. L. (2001). How students understand physics equations. Cognition and instruction, 19(4), 479-541.

Skemp, R. (1976). Instrumental understanding and relational understanding. Mathematics Teaching, 77, 20-26.

Skolverket. (2009). TIMSS Advanced 2008. Retrieved from http://www.skolverket.se/statistik-och-analys/internationella_studier/publikationer

Torigoe, E. (2008). What kind of math matters? A study of the relationship between mathematical ability and success in physics: ProQuest.

Tuminaro, J. (2004). A cognitive framework for analyzing and describing introductory students' use and understanding of mathematics in physics.

Tuminaro, J., \& Redish, E. F. (2007). Elements of a cognitive model of physics problem solving: Epistemic games. Physical Review Special Topics-Physics Education Research, 3(2), 020101.

UDIR. (1996). Læreplan for videregående opplæring, Fysikk, from http://www.udir.no/Lareplaner/Grep/Lareplanverket-for-videregaende-opplaringR94/\#Allmenne, økonomiske og administrative fag

Uhden, O., Karam, R., Pietrocola, M., \& Pospiech, G. (2011). Modelling Mathematical Reasoning in Physics Education. Science \& Education, 1-22.

Westera, W. (2001). Competences in education: a confusion of tongues. Journal of Curriculum studies, 33(1), 75-88. 